\title{
Single-well experimental design for studying residual trapping of supercritical carbon dioxide
}

\author{
Yingqi Zhang ${ }^{1}$, Barry Freifeld ${ }^{1}$, Stefan Finsterle ${ }^{1}$, Martin Leahy ${ }^{2,3}$, \\ Jonathan Ennis-King ${ }^{2,3}$, Lincoln Paterson ${ }^{2,3}$, Tess Dance ${ }^{2,3}$ \\ ${ }^{1}$ Lawrence Berkeley National Laboratory, Berkeley, CA,USA \\ ${ }^{2}$ CSIRO Petroleum, Clayton, Victoria, Australia \\ ${ }^{3}$ Cooperative Research Centre for Greenhouse Gas Technologies, Australia
}

\begin{abstract}
The objective of our research is to design a single-well injection withdrawal test to evaluate residual phase trapping at potential $\mathrm{CO}_{2}$ geological storage sites. Given the significant depths targeted for $\mathrm{CO}_{2}$ storage and the resulting high costs associated with drilling to those depths, it is attractive to develop a single well test that can provide data to assess reservoir properties and reduce uncertainties in the appraisal phase of site investigation. The main challenges in a single-well test design include (1) difficulty in quantifying the amount of $\mathrm{CO}_{2}$ that has dissolved into brine or migrated away from the borehole; (2) non-uniqueness and uncertainty in the estimate of the residual gas saturation $\left(S_{g r}\right)$ due to correlations among various parameters; and (3)the potential biased $S_{g r}$ estimate due to unaccounted heterogeneity of the geological medium. To address each of these challenges, we propose (1) to use a physical-based model to simulation test sequence and inverse modeling to analyze data information content and to quantify uncertainty; (2) to jointly use multiple data types generated from different kinds of tests to constrain the $S_{g r}$ estimate; and (3) to reduce the sensitivity of the designed tests to geological heterogeneity by conducting the same test sequence in both a water-saturated system and a system with residual gas saturation. To perform the design calculation, we build a synthetic model and conduct a formal analysis for sensitivity and uncertain quantification. Both parametric uncertainty and geological uncertainty are considered in the analysis. Results show (1) uncertainty in the estimation of $S_{g r}$ can be reduced by jointly using multiple data types and repeated tests; and (2) geological uncertainty is essential and needs to be accounted for in the estimation of $S_{g r}$ and its uncertainty. The proposed methodology is applied to the design of a $\mathrm{CO}_{2}$ injection test at CO2CRC's Otway Project Site, Victoria, Australia.
\end{abstract}

\section{Introduction and Objective}

The geologic sequestration of anthropogenic greenhouse gases to mitigate climate change is receiving increasing attention as a means to reduce atmospheric emissions and the related impacts as a result of continued use of fossil fuels. The ability of a host formation to effectively trap $\mathrm{CO}_{2}$ determines the suitability of a proposed site for long-term $\mathrm{CO}_{2}$ sequestration. Four trapping mechanisms have been identified (IPCC, 2005): structural trapping, residual phase trapping, solubility trapping and mineralization trapping. This study focuses on residual phase trapping, i.e., the immobilization of individual bubbles or relatively small blobs of the $\mathrm{CO}_{2}$-rich phase. The $\mathrm{CO}_{2}$ bubbles are either trapped by capillary forces or are stuck in local trapping structures or dead-end portions of the pore space, preventing further $\mathrm{CO}_{2}$ migration in response to pressure gradients or buoyancy forces. $\left(\mathrm{CO}_{2}\right.$ saturation can be reduced below the residual value by processes other than viscous flow, e.g., by compression or dissolution.) A parameter referred to as residual gas saturation $\left(S_{g r}\right)$ is used to characterize the tendency of a geologic formation to trap some of the non-wetting phase in its pore space. The residual gas saturation is a property of the interaction between the porous medium and the fluids, mostly reflecting the size and shape of its pores and their connectivity. However, residual gas saturation is not a static parameter; it depends on the sequence of hysteretic drainage and imbibition processes, i.e., it is history-dependent, with different values at each point in the storage formation as the fluid saturation changes during $\mathrm{CO}_{2}$ injection and redistribution. Only its maximum value $S_{\text {grmax }}$ (associated with the primary imbibition curve) can be considered as a formation parameter independent of the dynamic system 
state. The determination of the maximum residual gas saturation of a formation is both challenging and crucial as it will determine the ultimate capacity of a reservoir to residually trap $\mathrm{CO}_{2}$.

To achieve the pressure and temperature conditions required for supercritical $\mathrm{CO}_{2}$ storage, the depth of the target formation must have pressures of 72 bar or greater, with a temperature above $31^{\circ} \mathrm{C}$. In most sedimentary basins these conditions occur at depths greater than $800 \mathrm{~m}$ below ground surface. The high cost associated with drilling to such depths may limit the number of wells available for site characterization. Consequently, we believe there is significant value in developing a single-well appraisal methodology that can determine parameters critical for $\mathrm{CO}_{2}$ sequestration projects prior to full scale injection with acceptable accuracy.

The objective of this study is to propose a suite of single-well tests for quantifying the maximum residual gas saturation in brine aquifers. Although the maximum residual gas saturation is heterogeneous, an effective maximum residual gas saturation on the support scale of the test is the parameter more relevant to estimating $\mathrm{CO}_{2}$ storage capacity, and that is the parameter of interest in this work. The main difficulties in the test design for estimating $S_{g r}$ are: (1) due to the complexity of multiphase flow processes, there is no standard well test available for determination of $S_{g r}$. This requires us to use a process-based data analysis approach, i.e., an inversion analysis that is based on a process model; (2) correlations among various uncertain parameters lead to non-unique estimates of $S_{g r}$ (e.g., an observed high pressure increase during $\mathrm{CO}_{2}$ injection may be caused by either a high $S_{g r}$ or a low formation permeability; therefore, the pressure signal alone does not give us enough information to infer $S_{g r}$ ). This requires us to jointly use multiple types of data that are complementary to each other; (3) heterogeneity of aquifer properties and related uncertainty in fluid distribution after injection may lead to a biased estimate of $S_{g r}$. This requires us to design a test that is relatively insensitive to geological heterogeneity. Our proposed test sequence is designed to address the above challenges. We will (1) demonstrate how our approach arrives at a relatively reliable estimate of $S_{g r}$ through a synthetic example, and (2) demonstrate the approach by applying it for the design of the pilot injection at CO2CRC's Otway Project Site, Victoria, Australia. The proposed method is believed to be generally applicable to other $\mathrm{CO}_{2}$ injection projects.

\section{Design approach}

Single-hole testing, while being standard practice in groundwater hydrology, faces considerable challenges when considered for the characterization of multi-phase flow systems. Conventional single-well tests exploit the fact that the pressure perturbation (i.e., the signal analyzed by analytical or numerical well-test analysis methods) propagates through the geologic formation much farther and faster than the injected fluid itself. However, for the characterization of a multiphase system, or (as in this case) the determination of two-phase flow parameters of a formation that is currently under single-phase liquid conditions, it is necessary to create two-phase conditions, where the two-phase region around the wellbore is substantially smaller than the single-phase region that can be interrogated by the pressure perturbation in standard single-phase well testing. Furthermore, highly nonlinear multiphase processes and related phase transitions need to be captured for data analysis.

As a starting point for our test design, we consider a test sequence frequently used for oil reservoir characterization by (1) injecting $\mathrm{CO}_{2}$, (2) shutting-in the well to allow the injected $\mathrm{CO}_{2}$ to migrate and dissolve into the oil phase, and (3) producing the mobilized mixture back (Mohammed-Singh et al., 2006; Monger et al., 1991). This "Huff-n-Puff" methodology has been used as part of a $\mathrm{CO}_{2}$ sequestration demonstration at the Loudin Oil Field (Berger et al., 2009; Frailey and Finley, 2008) as part of an enhanced oil recovery (EOR) operation. If we apply the same procedure to a system that contains only brine (without oil), the amount of $\mathrm{CO}_{2}$ produced back can be used to approximate the amount of non-trapped $\mathrm{CO}_{2}$. In other words, the difference between the injected $\mathrm{CO}_{2}$ and produced $\mathrm{CO}_{2}$ is considered to be trapped, which in turn may allow determination of the residual gas saturation. This approach has a number of shortcomings. Foremost, the amount of $\mathrm{CO}_{2}$ not recovered is not necessarily trapped, but may not have been produced because $\mathrm{CO}_{2}$ either has dissolved into the brine or has migrated away from the injection zone due to buoyancy effects and escaped from the well's capture zone during production. Therefore, this method tends to overestimate long-term residual trapping. Even if the total volume of trapped $\mathrm{CO}_{2}$ were properly estimated, its spatial distribution in the formation remains unknown. Consequently, this method yields great uncertainty in the estimate of the residual $\mathrm{CO}_{2}$ saturation, which is the parameter of interest. Assumptions about the efficiency of brine displacement, and the geometry of the trapped $\mathrm{CO}_{2}$ plume after pull-back may be too simplistic for an accurate estimation of $S_{g r}$. In summary, simply calculating the mass balance, i.e., the difference between the amount of gas injected and recovered, may yield an upper estimate of trapped $\mathrm{CO}_{2}$ in a specific single-hole test, but does not allow the unique and accurate determination of residual gas saturation as a parameter that can be used for predictive simulations of $\mathrm{CO}_{2}$ trapping during sequestration operations.

Another potentially useful test is a partitioning tracer test run in an injection-withdrawal (push-pull) configuration from a single well. Partitioning tracer tests that are done between two wells are referred to as partitioning interwell tracer test (PITT). PITTs have been developed to detect crude oil (Cooke, 1971; Dean, 1971; Tang and Harker, 1991), measure water saturation (Imhoff et al., 2003; Li and Imhoff, 2005), and characterize and quantify nonaqueous phase liquid (e.g., NAPL) saturation (Deeds et al., 1999; Jin et al., 1995; Mariner et al., 1999; Nelson et al., 1999; Whitley et al., 1999; Young et al., 1999). In PITT, tracers are injected upstream and the recovered tracer breakthrough curves (BTCs) at the downstream extraction well are used to analyze tracer retardation, which is used to infer phase saturation. Single-well push-pull partitioning tracer tests have also been conducted to quantify properties for a wide range of aquifer physical, biological, and chemical characteristics, such as estimating solute retardation factors (Schroth et al., 2001); quantifying in situ rates of $\mathrm{CH}_{4}$ oxidation in soils (Gomez et al., 2008; Gonzalez-Gil et al., 2007; Urmann et al., 2008); and detecting and quantifying the presence of NAPL (Davis et al., 2002, 2005; Istok et al., 2002; Schroth et al., 2001).

A single-well partitioning push-pull tracer test includes (1) injecting water containing partitioning and conservative tracers into a well, (2) continuing to inject water to push the injected tracer away and allow tracer to partition into the nonaqueous phase liquid, which is assumed to be immobile, and (3) producing fluid back and measuring tracer concentrations. Because the injected tracer partially partitions into the nonaqueous phase liquid, recovered BTCs of tracers with higher nonaqueous phase liquid solubility are retarded with respect to more conservative tracers that preferably remain in the aqueous phase. Multiple tracers with different partitioning coefficients result in different BTCs that can be analyzed for the estimation of average immobile saturation of nonaqueous phase liquid. Tomich et al. (1973) used a reactive tracer (ethyl acetate) that is soluble in both the water and oil phases to hydrolyze and form ethanol, a second tracer, that is only soluble in water, and used the difference between the two tracers in a push-pull test to calculate the retardation factor and estimate the residual oil saturation. The recovered BTCs were analyzed by plotting the normalized concentration (concentration of extracted fluid divided by the initial injected solution concentration) versus the ratio between 2 the extracted volume and injected volume. Schroth et al. (2001) 
used numerical simulations to study the effects of retardation factors and (linear or nonlinear) sorption processes on the recovered BTCs in a homogeneous system. They concluded that the apparent dispersion increases with increased retardation factor. Davis et al. $(2002,2005)$ used radon that occurs naturally in groundwater as the partitioning tracer, along with injected water that contains a conservative tracer. Istok et al. (2002) analyzed the recovered BTCs of a few tracers from single-well push-pull tests with and without NAPL, to detect the presence of NAPL under both laboratory and field conditions. Although their study demonstrated that single-well partitioning tracer test can be used to detect NAPL, they concluded that additional research is needed to verify the ability of these tests to quantify NAPL saturation. All these studies (Davis et al., 2002, 2005; Istok et al., 2002; Nelson et al., 1999; Schroth et al., 2001) have pointed out that the presence of porous-medium heterogeneity and a variable distribution of immobile phase saturation can lead to reduced accuracy of the partitioning tracer test, and their impact on BTCs needs to be investigated.

Based on the results obtained with NAPLs, it can be expected that a single-well push-pull test also can be applied to quantify residual $\mathrm{CO}_{2}$ saturation in the field. However, estimation of residual gas saturation from tracer retardation is challenging because tracer properties (partitioning coefficient, diffusion coefficient) are uncertain given the high pressure and elevated temperature conditions expected at $\mathrm{CO}_{2}$ injection sites and the measurement of tracer concentrations carries experimental errors. Moreover, the inherent heterogeneity of the geological formation and the assumption of "instant equilibrium partitioning" used to analyze tracer data leads to uncertain and non-unique estimates of residual gas saturation.

The test design proposed below aims at overcoming these limitations. Moreover, the design should ensure that sufficiently sensitive data are collected that contain the information needed to enable inference of the parameters of interest with acceptably low estimation uncertainty. This is achieved through (1) a forward numerical model that is capable of simulating non-isothermal, multicomponent, multiphase flow processes to simulate the test sequence; and (2) an inverse modeling analysis to optimize the test design: to determine information content of data sets through systematic sensitivity analyses and to examine estimation uncertainty using synthetic data inversions. Two principles are followed in the design: (1) perform a test sequence that yields multiple types of complementary data to constrain the estimate of $S_{g r}$; and (2) remove or reduce the bias caused by the heterogeneity of the storage formation by repeating the same test under different saturation conditions.

We propose to use a combination of three tests performed before and after $\mathrm{CO}_{2}$ injection: a hydraulic test, a thermal test, and a push-pull partitioning tracer test. The basic idea is to (1) perform this series of hydraulic, thermal and tracer tests under fully water-saturated conditions (referred to as reference tests; Stage 1); (2) create a system at residual $\mathrm{CO}_{2}$ saturation (Stage 2); (3) repeat the sequence of hydraulic, thermal and tracer tests in the formation containing residual $\mathrm{CO}_{2}$ (referred to as characterization tests; Stage 3); and (4) analyze data from all three stages and estimate $S_{g r}$. Performing reference tests provides information for single-phase parameters. As a result, the reduced uncertainty in these parameters will help to constrain two-phase parameters. The individual tests can be described as follows:

A. Hydraulic test: In the hydraulic test, water is injected into the formation (which may be fully liquid saturated or contain gas), and pressure transients are recorded and utilized to infer the amount of gas trapped in the formation. Pressure data are sensitive to residual gas saturation because pressure change depends on relative permeability, which depends on residual gas saturation. When water is injected into (a) a fully water-saturated formation; (b) a formation at residual gas saturation with a low $S_{g r}$; and (c) a formation at residual gas saturation with a high $S_{g r}$, the liquid relative permeability is highest in (a) and lowest in (c), which means the pressure pulse in case (a) can move away from the vicinity of the well much faster than in cases (b) and (c). Therefore, the pressure increase in case (c) is the highest, even though the effect is somewhat countered by the increase in storativity as gas saturation is increased. Inherent heterogeneity effects are reduced by comparing the pressure response in a formation at residual gas saturation with the reference test response.

B. Tracer test: Tracer is injected into the formation and pushed further away from the injection well by continuous injection of water, before being pulled back into the borehole, where a breakthrough curve (BTC) is measured. Tracer breakthrough curves are sensitive to residual gas saturation because a portion of tracer will partition into the gas, becoming immobile, and thus will not be produced back. Tracer partitioning between water and gas is governed by Henry's law, which states that at constant temperature, the amount of a given gas dissolved in a given type and volume of liquid is directly proportional to the partial pressure of that gas in equilibrium with that liquid. This proportionality constant, which is also temperature dependent, is known as Henry's coefficient. Pruess et al. (2005) provides Henry's coefficients for a list of potential noble gases (such as $\mathrm{Ar}, \mathrm{Kr}, \mathrm{Xe}$ ) that can be used as tracers. Once tracer is injected into a formation that contains residual gas, part of the tracer partitions into the gas and becomes immobile (to advective forces). The amount of tracer that remains in the water is mobile and can be produced during the pull-back phase of the test. Then, $S_{g r}$ can be inferred based on the amount of tracer that is recovered. Two comparisons can be made using the tracer breakthrough curves: (1) for the same tracer, we compare the BTCs from Stage 1 and Stage 3 , the differences of which can be used to infer $S_{g r}$; (2) for two tracers with different partitioning coefficients, we can compare their recovery curves from the same test to estimate $S_{g r}$. Use of both comparisons can help reduce the uncertainty in the estimation of $S_{g r}$. In this test, we propose to use noble gases as tracers, because (1) they partition between the aqueous and $\mathrm{CO}_{2}$-rich phase, (2) they are chemically inert and non-hazardous, and (3) they can be measured with great precision. We propose to use two noble gases with distinct partitioning coefficients and compare the BTCs obtained from the residual gas field (Stage 3) with the BTCs from the reference test (Stage 1).

C. Thermal test: In the thermal test, the borehole is heated and temperature data are recorded. Temperature data are sensitive to residual gas saturation because temperature change during thermal perturbation depends on thermal diffusivity, which depends on fluid composition, i.e., the amount of $\mathrm{CO}_{2}$ in the system. Supercritical $\mathrm{CO}_{2}$ has a significantly smaller thermal diffusivity than water (e.g., at $65^{\circ} \mathrm{C}$ and $14.5 \mathrm{MPa}$, for a sand formation with a porosity of $20 \%$, a specific heat capacity of $800 \mathrm{~J} /\left(\mathrm{kg}^{\circ} \mathrm{C}\right)$, when it is fully water saturated, the effective thermal conductivity is about $2.2 \mathrm{~W} /(\mathrm{m} \mathrm{K})$ and diffusivity about $8.9 \times 10^{-7} \mathrm{~m}^{2} / \mathrm{s}$; when it is fully $\mathrm{CO}_{2}$ saturated, the effective thermal conductivity is about $1.4 \mathrm{~W} /(\mathrm{m} \mathrm{K})$, and its diffusivity is about $\left.6.8 \times 10^{-7} \mathrm{~m}^{2} / \mathrm{s}\right)$. We can take advantage of the contrast between the thermal diffusivity of a brine-saturated formation and one that contains $\mathrm{CO}_{2}$ by performing a heat transport test in which the temperature response is used to estimate gas saturation. Freifeld et al. (2008) described the basic mechanics of such a test, including the deployment of a fiber-optic distributed temperature sensor (DTS) and a resistance heater, and the analysis of the collected temperature data for estimating formation thermal conductivity in situ. In addition, the application of thermal monitoring to $\mathrm{CO}_{2}$ storage has been demonstrated as part of the CO2SINK experiment (Freifeld 


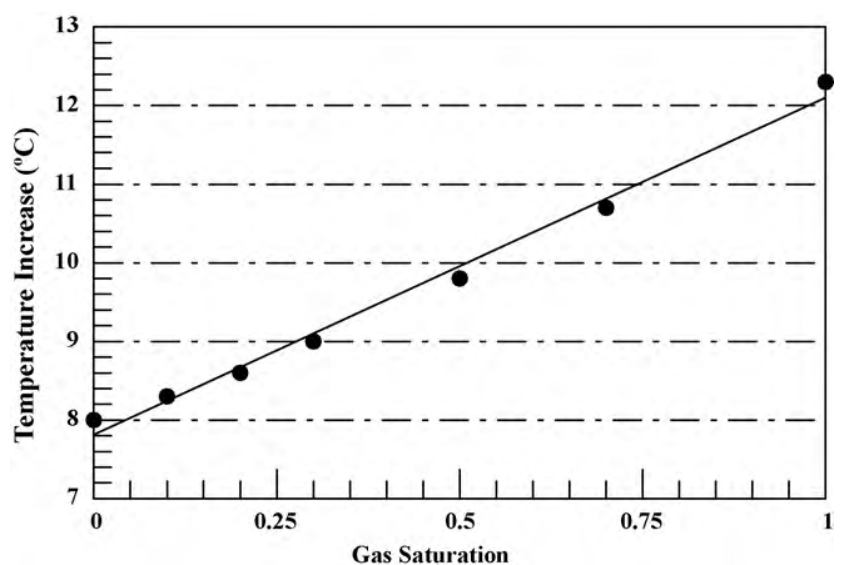

Fig. 1. Maximum temperature after 2 days of heating at $40 \mathrm{~W} / \mathrm{m}$ for systems with different gas saturations.

et al., 2009; Giese et al., 2009). Fig. 1 shows the temperature increase as a function of saturation (assuming a uniform distribution of $\mathrm{CO}_{2}$ ) after 2 days of heating at $40 \mathrm{~W} / \mathrm{m}$ of a system that is initially at $65^{\circ} \mathrm{C}$. For such a system, a temperature change of $0.1^{\circ} \mathrm{C}$ corresponds to a saturation difference of 0.02 . The temperature increase is directly proportional to gas saturation. One of the benefits of using temperature transients as a proxy measurement to estimate $S_{g r}$ is the high accuracy and relative simplicity in monitoring thermal response. Given a typical DTS measurement accuracy of $\pm 0.1^{\circ} \mathrm{C}$ (with a repeatability of $0.03^{\circ} \mathrm{C}$ ), we are able to detect $\mathrm{CO}_{2}$ saturation changes smaller than 0.05 . In addition, the depth of penetration of the thermal front into the formation (1-2 m) is significantly greater than alternative wellbore logging methods (i.e., a pulsed neutron capture tool, which only penetrates about $20 \mathrm{~cm}$ ).

\section{Test sequence}

In the design of the test sequence, special attention needs to be given to Stage 2 , i.e., the creation of a region around the well near residual $\mathrm{CO}_{2}$ saturation. (Note that the inverse modeling approach applied here does not require that the field in Stage 3 is precisely at residual saturation, because the observed system behavior is sensitive to $S_{g r}$ for all saturations greater than $S_{g r}$. Nevertheless, we propose that the system state be close to residual saturation to maximize the sensitivity and to reduce the amount of extrapolation needed.) We have considered two approaches to creating a residual gas field: the first approach is to produce the mobile gas back and leave the trapped gas in the formation. This approach may be impractical or fail, because withdrawal of $\mathrm{CO}_{2}$ slows down asymptotically as the residual gas saturation is approached, requiring the production of substantial brine volumes, into which the trapped $\mathrm{CO}_{2}$ may gradually dissolve. Long testing time, the production of a large amount of brine, and the uncontrollable dissolution of $\mathrm{CO}_{2}$ with an uncertain final saturation state make this approach unfeasible for our purposes. As an alternative, water saturated with $\mathrm{CO}_{2}$ can be injected after $\mathrm{CO}_{2}$ injection, pushing away the mobile gas from the well vicinity and leaving behind trapped $\mathrm{CO}_{2}$ at its residual saturation. The co-injection of a small amount of $\mathrm{CO}_{2}$ is essential to prevent $\mathrm{CO}_{2}$ dissolution into the liquid phase. The proposed test sequence of each stage is summarized in Table 1 and Fig. 2.

The duration of each test as well as injection and withdrawal rates are site specific and should be chosen to maximize the information content of the data collected within operational constraints. The volume of reservoir interrogated by each test is also site specific and different for the three test types. In general, the smallest scale is investigated during the temperature test (1-2 m), a medium scale is investigated by the tracer test (tens of meters), and the largest scale is investigated by the pressure test (tens to hundreds of meters). This variation in spatial scale is a function of the diffusivity that governs each process. Given that the actual gas saturation distribution around the well is unknown, and that an effective, average parameter capturing residual gas trapping is sought, our approach of combining data from three test types that are based on different physical properties and predicated on different support scales adds to the overall robustness and representativeness of the estimated residual gas saturation parameter.

In this paper we explore through numerical simulations the time-series data of pressure, temperature, and tracer concentration that would be acquired during field studies. Based on synthetic data sets generated using a heterogeneous reservoir (modeled after con-

Table 1

Test sequence.

\begin{tabular}{|c|c|c|c|}
\hline Test & Description & Duration & Data \\
\hline \multicolumn{4}{|c|}{ Stage 1: reference tests } \\
\hline \multirow[t]{2}{*}{ Thermal } & Heating & 2 days & \multirow[t]{2}{*}{ Temperature (T1) } \\
\hline & Cooling & 3 days & \\
\hline \multirow[t]{2}{*}{ Hydraulic } & Water injection & 1 day & \multirow[t]{2}{*}{ Pressure (P1) } \\
\hline & Pull-back & 7 days & \\
\hline \multirow[t]{2}{*}{ Tracer } & Tracer pulse & $2 \mathrm{~h}$ & - \\
\hline & Pull-back & 7 days & Concentration (C1) \\
\hline \multicolumn{4}{|c|}{ Stage 2: creation of system with residual gas } \\
\hline \multirow[t]{6}{*}{ Optional thermal } & Heating & 2 days & \multirow[t]{2}{*}{ Temperature (T2) } \\
\hline & Cooling & 3 days & \\
\hline & $\mathrm{CO}_{2}$ injection & 2 days & \multirow[t]{2}{*}{ Pressure (P2) } \\
\hline & Shut-in & 1 day & \\
\hline & Water injection $\left(\mathrm{CO}_{2}\right.$ saturated) & 2 days & \multirow[t]{2}{*}{ Pressure (P3) } \\
\hline & Shut-in & 1 day & \\
\hline \multicolumn{4}{|c|}{ Stage 3: characterization tests } \\
\hline \multirow[t]{2}{*}{ Thermal } & Heating & 2 days & \multirow[t]{2}{*}{ Temperature (T3) } \\
\hline & Cooling & 3 days & \\
\hline \multirow[t]{2}{*}{ Hydraulic } & Water injection & 1 day & \multirow[t]{2}{*}{ Pressure (P4) } \\
\hline & Pull-back & 7 days & \\
\hline \multirow[t]{2}{*}{ Tracer } & Tracer pulse & $2 \mathrm{~h}$ & - \\
\hline & Pull-back & 7 days & Concentration (C2) \\
\hline
\end{tabular}




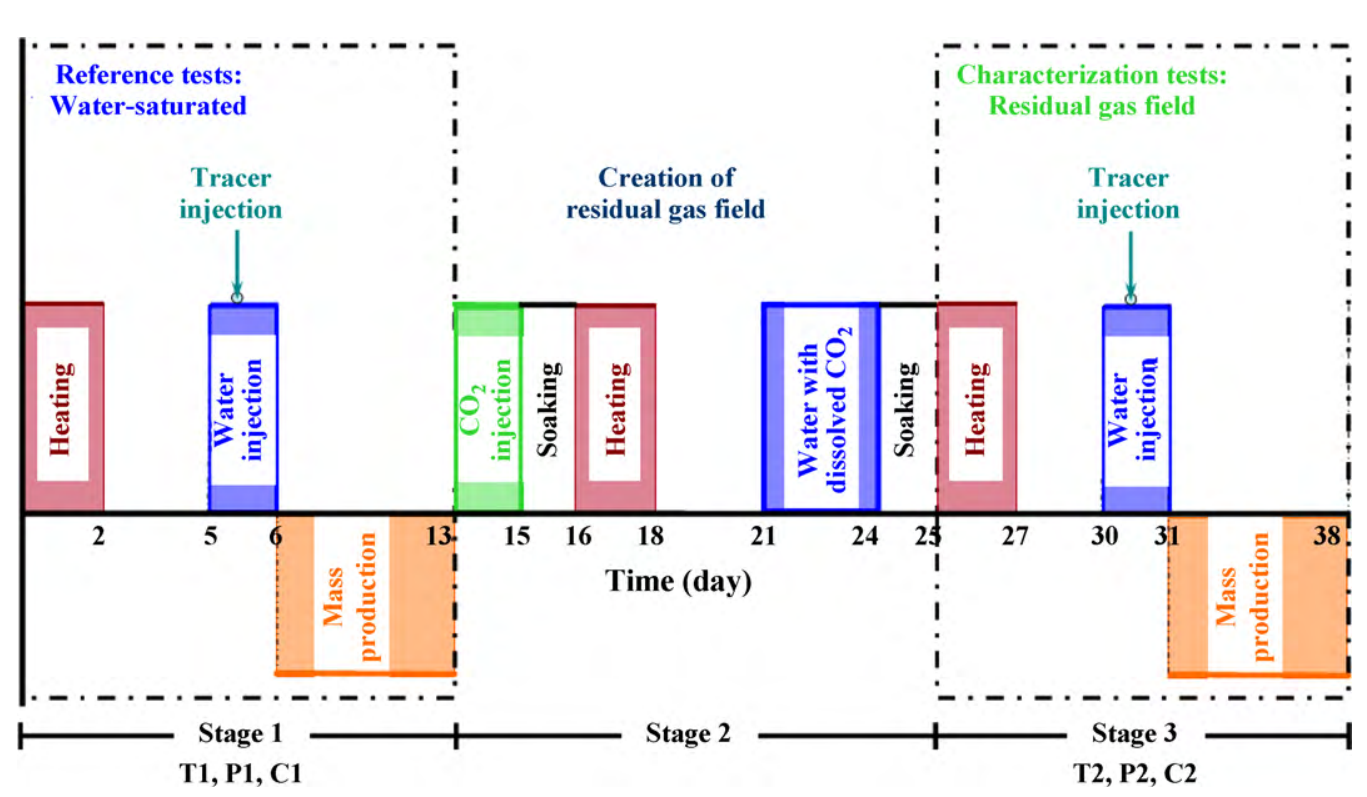

Fig. 2. Proposed test sequence.

ditions at Otway), we will infer entrapped gas volume and residual gas saturation.

\section{Analysis of proposed test design}

This section includes two numerical analyses to examine the ability of the proposed approach to identify the residual trapping mechanism and its key parameters. The first analysis is a synthetic case, in which we consider various sources of uncertainty and demonstrate that the joint use of multiple data sets and joint use of reference and characterization tests improves the estimate of $S_{g r}$. For this analysis, a numerical model accounting for supercritical $\mathrm{CO}_{2}$ injection into a heterogeneous brine formation is used to generate a set of synthetic observation data for sensitivity and inversion analyses. Gravity is explicitly accounted for. We will present the analysis results from simulations using a 3D model. Analyses are also conducted using a 2D model. The comparison of the two sets of results can help us to determine the appropriateness for using a 2D model for design calculations. In the second analysis, we discuss the approach in the context of the Otway $\mathrm{CO}_{2}$ injection pilot test design.

Simulations are conducted using the EOS7C module of TOUGH2 (Pruess et al., 1999), a numerical simulator for non-isothermal multiphase, multicomponent flows in porous media. EOS7C(Oldenburg et al., 2004) was developed to model gas mixtures of methane and a non-condensible gas (in our case: $\mathrm{CO}_{2}$ ), with one tracer present. This EOS module is incorporated in the iTOUGH2 (Finsterle, 2004) simulation-optimization code in preparation for formal sensitivity analyses and parameter identification. We use the inverse modeling capabilities of iTOUGH2 to calculate sensitivity and covariance matrices. The focus of this study is to demonstrate how multiple data sets and multiple tests can be jointly used to estimate $S_{g r}$ and its uncertainty.

Hysteresis is not included in the current study, even though it is expected that hysteresis in the capillary pressure and specifically the relative permeability functions plays a key role in the plume behavior and $\mathrm{CO}_{2}$ trapping for an actual injection scenario (Doughty, 2007), and also during the proposed single-well test with its alternating drainage and imbibition sequence. However, while the absolute amount of $\mathrm{CO}_{2}$ trapped depend on the subtleties in the hysteretic model, the design calculations discussed here are mainly concerned with relative changes in the variables observed during the well test. We acknowledge that accounting for hysteresis will lead to more complex process simulations and additional parameters that need to be determined, which in turn lead to higher estimation uncertainty. Examination of this more realistic, hysteretic system is subject of future research and may need to be considered when the proposed approach is applied for the analysis of actual field data.

\subsection{Synthetic case analysis}

The main purposes of this analysis are to investigate how various uncertainties affect the estimate of $S_{g r}$ and how the

Table 2

Summary of uncertain parameters and expected variation.

\begin{tabular}{|c|c|c|c|c|}
\hline Parameter & Units & Value & Variability & \\
\hline Residual gas saturation, $S_{g r}$ & - & 0.2 & 0.1 & \\
\hline Residual liquid saturation, $S_{l r}$ & - & 0.1 & 0.1 & \\
\hline $\log _{10}$ (horizontal permeability, $k$ ) & $\log _{10}\left(\mathrm{~m}^{2}\right)$ & -12 & 0.5 & \\
\hline Porosity, $\phi$ & - & 0.28 & 0.05 & \\
\hline van Genuchten parameter, $n$ & - & 3 & 0.6 & \\
\hline $\log _{10}$ (pore compressibility, $c_{\phi}$ ) & $\log _{10}\left(\mathrm{~Pa}^{-1}\right)$ & -8.5 & 0.5 & \\
\hline Heat conductivity, dry, $\lambda_{d r y}$ & $\mathrm{~W} \mathrm{~m} \mathrm{~m}^{-1} \mathrm{~K}^{-1}$ & 1.4 & 0.1 & \\
\hline Heat conductivity, wet, $\lambda_{\text {wet }}$ & $\mathrm{W} \mathrm{m} \mathrm{m}^{-1} \mathrm{~K}^{-1}$ & 2.2 & 0.1 & \\
\hline $\log _{10}$ (inverse Henry coefficient, $H^{-1}$ ) & $\log _{10}\left(\mathrm{~Pa}^{-1}\right)$ & -9.42 & 0.5 & \\
\hline Correlation length (geostatistical parameter) aa & $\mathrm{m}$ & 20. & 5.0 & \multirow{3}{*}{5} \\
\hline Injection rate factor (fi) & - & 1.0 & 0.1 & \\
\hline Production rate factor (pi) & - & 1.0 & 0.1 & \\
\hline
\end{tabular}



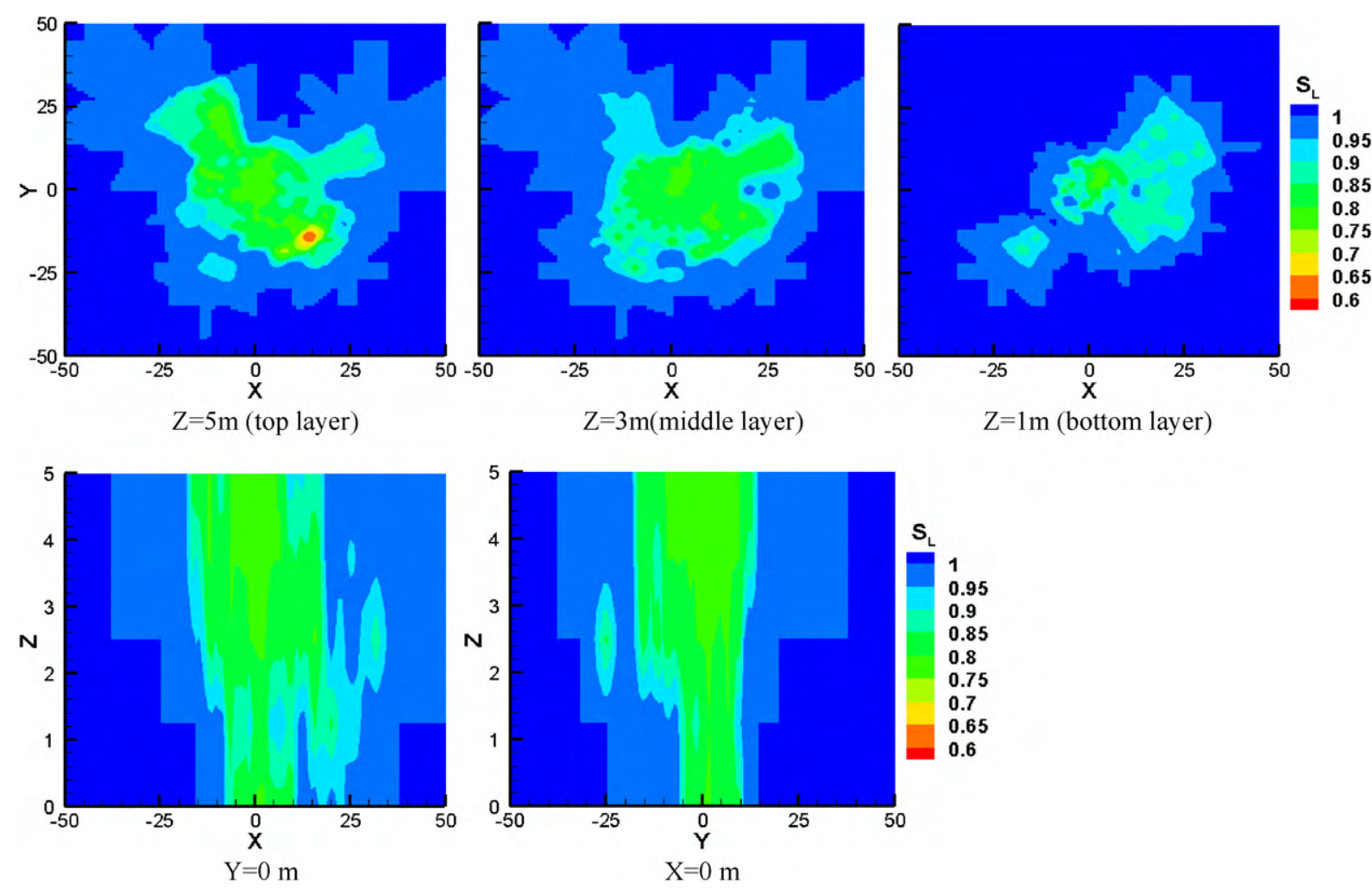

Fig. 3. Liquid saturation at the end of 24 days.

joint use of different types of data and tests can help constrain the final estimate. For these purposes, we present analysis results conducted using a $3 \mathrm{D}$ model. $\mathrm{CO}_{2}$ is assumed to be injected into a $5 \mathrm{~m}$ thick reservoir. The lateral extent of the model is $1 \mathrm{~km}$. Geostatistical simulation techniques implemented in iTOUGH2 (Finsterle and Kowalsky, 2008) are used to generate a heterogeneous field of log-permeability modifiers with a correlation length of $20 \mathrm{~m}$ in the horizontal direction and $1 \mathrm{~m}$ in the vertical direction. The capillary-strength parameter $\alpha$ of the van Genuchten constitutive relationships (Genuchten, 1980) is linked to the heterogeneous permeability field $k$ according to the Leverett scaling rule, $\alpha_{2}=\alpha_{1} \sqrt{k_{2} / k_{1}}$ (Leverett, 1941). A set of synthetic observation data for the test sequence described above is generated using the parameter values listed in Table 2.

Fig. 3 shows liquid saturation distributions after residual gas field is created (i.e., at 24 days) at three different elevations and for two vertical cross sections. We observe that $\mathrm{CO}_{2}$ distribution is highly non-uniform, with more $\mathrm{CO}_{2}$ at the top layer due to buoyancy effects, and horizontal patterns that different significantly from radial symmetry of a homogeneous system. $\mathrm{CO}_{2}$ saturation may be locally higher even relatively far away from the injection point as a result of heterogeneity. For example, the lowest liquid saturation seen in the top layer occurs away from the injection interval at a location with a high permeability, where gas enters relatively easily due to the corresponding weak capillary pressure (a correlation accounted for by the Leverett scaling).

In addition, we conduct similar analyses using a 2D radial model. Comparison of the $2 \mathrm{D}$ and $3 \mathrm{D}$ results help identify the relative importance of the heterogeneity structure (a realistic 3D field vs. a simplified, radially symmetric property distribution) on the evaluation of the test design.

\subsubsection{Uncertainty quantification}

Two types of uncertainty are considered: parametric uncertainty and uncertainty from geological heterogeneity. In addition to $S_{g r}, 11$ parameters are considered uncertain, including hydrological parameters, thermal parameters, transport parameters, geological parameters and operational parameters. Table 2 contains the parameter values for which the sensitivity and uncertainty analyses are performed, along with their expected variation, which is used to normalize sensitivity coefficients. At the design stage, it is important to consider the major sources of uncertainty, maintaining the model complexity at a level appropriate for the intended analysis. Therefore, although residual liquid saturation $\left(S_{l r}\right)$ is correlated to rock permeability and porosity (Holtz, 2006), residual liquid saturation effects are represented by a single, albeit uncertain parameter. Geological uncertainty refers to the random component of the spatial variability, i.e., the unknowable details of the heterogeneous permeability field. Note that irreducible geological uncertainty exists even though the geostatistical parameters of the permeability field may be known. We will first only consider parametric uncertainty, then add in geological uncertainty to examine its effect on the estimation uncertainty of $S_{g r}$.

4.1.1.1. Parametric uncertainty. To investigate parametric uncertainty, sensitivity analyses with different combinations of data presumed available are performed. A dimensionless sensitivity coefficient is calculated as a relative measure of information content of a single observation point. It is defined as the ratio of change of the model output (i.e., the observable system response at the point in space and time where data are to be collected) over the change of the model input (i.e., the uncertain parameter to be estimated), scaled by the assumed measurement noise and expected parameter variation. Results of each type of output data at the two 6 stages to the 12 uncertain parameters are plotted in Fig. 4. The sum 


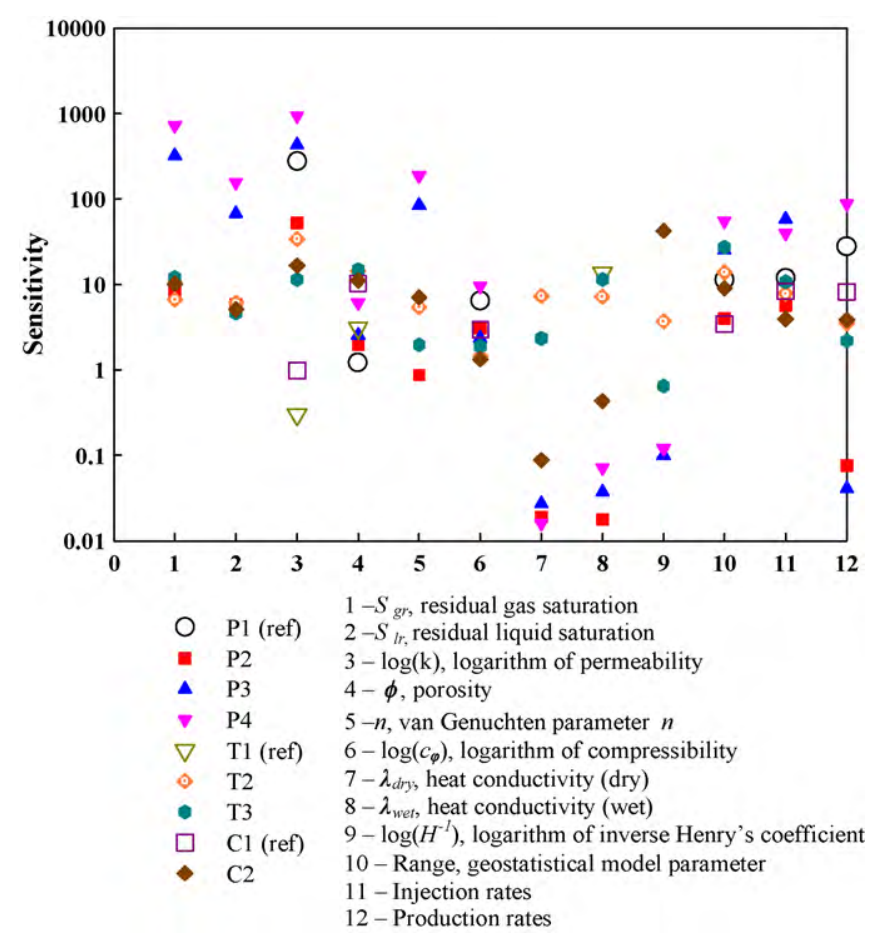

Fig. 4. Sensitivity of each output data set to different input parameters. Numerals on the $\mathrm{X}$-axis refer to uncertain input parameters.

of the absolute values of the sensitivity coefficients for each data set indicates how much information each test contains with respect to the parameters.

While high sensitivity is necessary to determine the parameters of interest, strong correlations among the parameters may nevertheless lead to a large variance in our parameter estimates. A high estimation uncertainty (defined as the variance of the estimated parameter) is revealed by the diagonal elements of the parameter covariance matrix, which is calculated based on a linearity and normality assumption. Recalculating the parameter covariance matrix using different synthetic data sets indicates how estimation uncertainty may be reduced by using multiple data types and multiple tests. The estimation uncertainty of $S_{g r}$ is likely to be small if we assume that all the other parameters are perfectly known. To avoid reaching an overly optimistic conclusion, it is essential to include all relevant parameters in the analysis to account for correlations of these parameters to $S_{g r}$, which may significantly increase its estimation uncertainty to a more realistic value. To demonstrate how each kind of observation helps constrain the estimate of $S_{g r}$, the estimation covariance matrix is calculated assuming that (1) only data from Stages 2 and 3 are available (i.e., no reference tests were performed); (2) only one type of data is available (i.e., either pressure, temperature or tracer data); (3) two types of data are available (any combination of pressure, temperature or tracer data); and (4) all three data types are available. Data listed in (2)-(4) include data from all three stages of the test sequence. The standard deviations of each uncertain parameter are listed in Table 3.

Although some of the geostatistical parameters are considered uncertain, the random component of the spatial variability referred to as geological uncertainty was removed by employing the same seed number for the creation of the permeability field in the linear error analysis as that used to generate the synthetic observation data. (Geological uncertainty is analyzed in the next subsection.)

Information from Fig. 4 and Table 3 are complementary to each other. Fig. 4 shows that pressure data P4 in the characterization tests have a large sensitivity to the parameter of interest, $S_{g r}$. However, pressure also has the largest sensitivity to almost all the other uncertain formation parameters with a few exceptions: dry heat conductivity is most sensitive to T2 (temperature data at maximum $\mathrm{CO}_{2}$ saturation); wet heat conductivity is most sensitive to T1 (temperature data under single-phase liquid conditions); Henry's coefficient is most sensitive to C2 (tracer data in the characterization test), etc. Therefore, if a different pressure signal were obtained during the characterization tests, it is very difficult to determine which parameter is responsible for it. As a result, if only pressure data from the characterization tests were used, the estimation uncertainty for $S_{g r}$ would be 0.08 . While estimation uncertainty would be at a similar level (0.06) if only temperature data were used, the uncertainty would be much higher if only concentration data were used. This is partly because fewer concentration calibration data are available as none are collected in Stage 2 (unlike pressure and temperature data). However, the sensitivity of tracer data could be improved by using two dissimilar tracers, which result in more calibration points. When two types of data are used jointly, the estimation uncertainty is reduced due to the reduced parameter correlation; e.g., if both pressure and temperature data are available, the estimation uncertainty is reduced to 0.02 . If all three types of data are used, this number is further reduced to 0.017 .

Data from the reference tests (P1, T1 and C1) contain valuable information about the system under single-phase conditions. Including these data in the inversion helps determine single-phase parameters and other formation characteristics (e.g., heterogeneity). This independent estimation thus reduces the correlations among the parameters once two-phase conditions are invoked by gas injection, or lessens the negative impact of these correlated parameters on the estimate of $S_{g r}$. This can be clearly demonstrated for permeability $\left(\log _{10}(k)\right)$, whose estimation uncertainty is reduced by $50 \%$ if reference tests are performed. Reduction of

Table 3

Estimation uncertainties assuming different available data sets.

\begin{tabular}{|c|c|c|c|c|c|c|c|c|c|}
\hline \multirow[t]{2}{*}{ Parameter } & \multirow{2}{*}{$\begin{array}{l}\text { Without reference tests } \\
\text { All }\end{array}$} & \multicolumn{7}{|c|}{ With reference tests } & \multirow{2}{*}{$\begin{array}{l}\text { With geological uncertainty } \\
\text { All }\end{array}$} \\
\hline & & $\mathrm{P}$ & $\mathrm{T}$ & C & $\mathrm{P}+\mathrm{T}$ & $\mathrm{P}+\mathrm{C}$ & $\mathrm{C}+\mathrm{T}$ & All & \\
\hline$S_{g r}$ & 0.03 & 0.08 & 0.06 & 0.93 & 0.020 & 0.04 & 0.03 & 0.017 & 0.03 \\
\hline$S_{l r}$ & 0.08 & 0.20 & 0.06 & 0.81 & 0.04 & 0.15 & 0.05 & 0.04 & 0.11 \\
\hline $\log _{10}(k)$ & 0.06 & 0.30 & 0.13 & 3.71 & 0.04 & 0.15 & 0.07 & 0.03 & 0.19 \\
\hline$\phi$ & 0.02 & 0.15 & 0.02 & 0.16 & 0.01 & 0.04 & 0.01 & 0.01 & 0.05 \\
\hline$n$ parameter & 0.39 & 1.73 & 0.86 & 10.0 & 0.39 & 0.76 & 0.42 & 0.30 & 0.81 \\
\hline $\log _{10}\left(c_{\varphi}\right)$ & 0.70 & 1.28 & 1.40 & 6.52 & 0.59 & 1.05 & 0.69 & 0.44 & 1.39 \\
\hline$\lambda_{d r y}$ & 0.20 & 9.93 & 0.18 & $2.3 e 3$ & 0.12 & 9.51 & 0.11 & 0.09 & 0.52 \\
\hline$\lambda_{\text {wet }}$ & 0.12 & 7.81 & 0.03 & 7.69 & 0.03 & 2.80 & 0.03 & 0.03 & 0.08 \\
\hline $\log _{10}\left(H^{-1}\right)$ & 0.09 & 32.3 & 0.73 & 3.18 & 0.66 & 0.22 & 0.08 & 0.08 & 0.24 \\
\hline aa & 1.11 & 2.39 & 2.00 & 18.7 & 1.16 & 2.08 & 1.45 & 1.06 & 4.74 \\
\hline fi & 0.04 & 0.40 & 0.06 & 0.80 & 0.05 & 0.22 & 0.04 & 0.03 & 0.13 \\
\hline pi & 0.04 & 0.40 & 0.20 & 0.87 & 0.05 & 0.21 & 0.07 & 0.03 & 0.13 \\
\hline
\end{tabular}



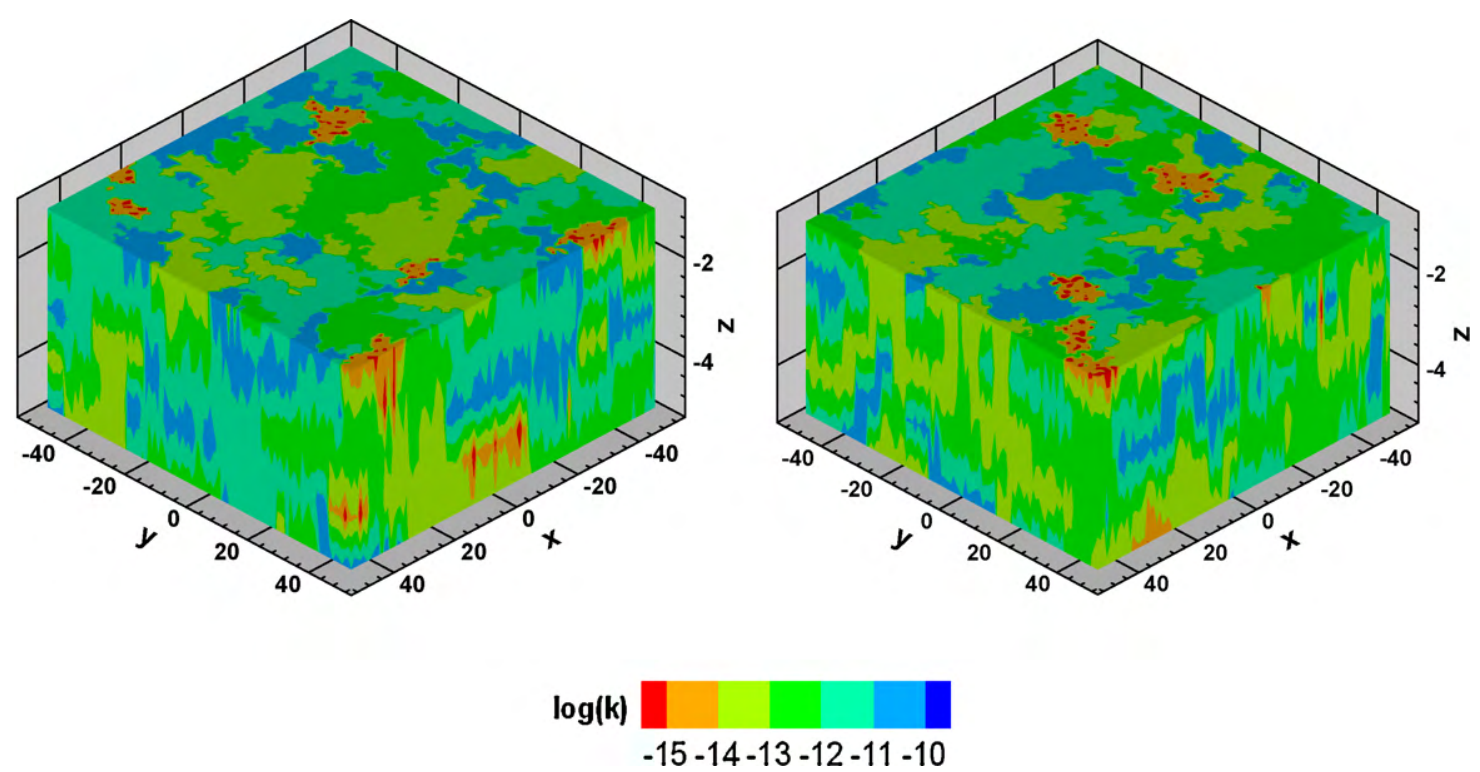

Fig. 5. Examples of permeability fields near the well for quantifying geological uncertainty: logarithm of horizontal permeability $k\left(\mathrm{~m}^{2}\right)$.

permeability uncertainty and other related parameters lead to a reduced estimation uncertainty of $S_{g r}$.

The values in Table 3 provide design guidelines rather than quantitative predictions of final estimation uncertainty. The following issues have to be considered: (1) The sensitivity and uncertainty analyses are performed at a single point in the parameter space. Given the nonlinear nature of the forward and inverse problems, different values will be obtained for other parameter combinations. (2) The estimation uncertainties listed in Table 3 may be too optimistic, because they are based on the assumption that the observed data can be matched to within measurement precision. Furthermore, conceptual modeling errors (e.g., incorrect relative permeability and capillary pressure functions, an incorrect geostatistical model) are not accounted for in this analysis. Nevertheless, these uncertainty analyses provide information on the relative information content of each data type and data set. Table 3 demonstrates that the joint use of multiple data types and the inclusion of reference test data will substantially increase our ability to determine the residual gas trapping capability of a $\mathrm{CO}_{2}$ storage formation.

4.1.1.2. Geological uncertainty. To study the impact of geological uncertainty on parameter estimation errors, multiple synthetic inversions are performed using 17 permeability fields created by varying the seed number. The hydrological, thermal, transport, geostatistical and operational parameters are estimated concurrently using both data from reference tests and characterization tests. Noise is added to observation data to mimic potential measurement errors. The geological uncertainty is calculated based on the sample statistics of the estimates from these inversions. Fig. 5 shows two examples of the permeability field that are used in the quantification of the geological uncertainty. The estimation uncertainties considering geological variability are listed in the last column of Table 3 . When geological uncertainty is considered, the estimation uncertainties for all parameters are larger than those obtained above without the inclusion of geological uncertainty; specifically, the estimation uncertainty for $S_{g r}$ is about 0.03 . It is important to point out that this estimation uncertainty is still optimistic since (1) the applied geostatistical model may not correctly represent the heterogeneity field; (2) there are additional uncertain parameters that are assumed to be perfectly known in the analysis. To reduce geological uncertainty, (1) vertical measure- ments from the well logs, or, if possible, measurements performed on recovered core should be used as conditioning points during the generation of the permeability field; and (2) geophysical measurements and imagining technologies could be employed during $\mathrm{CO}_{2}$ injection and integrated into the inversion analyses. This will reduce the geological uncertainty in the vicinity of the injection area.

While the uncertainty in the estimation of $S_{g r}$ has increased when accounting for geological uncertainty, the joint interpretation of the combined hydraulic, thermal, and tracer tests provides a reasonable design basis for which to assess the efficacy of residual trapping. Accounting for geological uncertainty in the estimation of $S_{g r}$ has thus been demonstrated to be essential to providing a realistic assessment of potential estimation errors, and can be accomplished by performing stochastic inversions.

\subsubsection{D radial model vs. $3 D$ model}

The 3D analyses discussed above were repeated using a 2D radial model. Because of the forward process model needs to include nonisothermal, multiphase flow physics for correctly representing the dynamic behavior of the simulated system, it is much more difficult and time-consuming to perform an inverse analysis using a 3D model compared to a 2D model. However, a 2D radial model misrepresents heterogeneity (i.e., ring-shape heterogeneity). The goal of this subsection is to investigate the possibility of using a $2 \mathrm{D}$ radial model for a more efficient analysis by comparing its results to those of the 3D model.

In general, the estimation uncertainty results obtained from a 2D radial model are in qualitative agreement with the results from a 3D model without considering geological uncertainty. However, after geological uncertainty is added, the estimation uncertainty increases more for the 2D radial model. To summarize this comparison, we found that when considering pressure, temperature, and tracer tests combined with geologic uncertainty the residual gas saturation estimation uncertainty is 0.07 for the $2 \mathrm{D}$ radial model and 0.03 for the 3D model. This higher uncertainty for the $2 \mathrm{D}$ radial model is due to the fact that heterogeneity is encountered in serial mode in the dominant (radial) flow direction, increasing the impact of low-permeability regions. During the design stage, when the simulation purpose is to find the information content of potential observation data, it is sufficient to use a 2D radial model. However, 8 if the goal is to estimate site-specific parameters, it is important 
to correctly represent heterogeneity of the system based on prior knowledge, thus a 3D model should be used.

\subsection{Application to Otway Project}

Recognizing the importance of saline aquifers for $\mathrm{CO}_{2}$ storage, the CO2CRC Otway Project proposed to conduct a single-well test aimed at better understanding residual trapping mechanisms and the related formation parameters. A pre-determined volume of $\mathrm{CO}_{2}$-rich gas $\left(80 \% \mathrm{CO}_{2}\right.$ and $20 \% \mathrm{CH}_{4}$ by volume; or $90 \% \mathrm{CO}_{2}$ and $10 \% \mathrm{CH}_{4}$ by mass) will be injected at a supercritical state into the Paaratte Formation. The composition of the injection gas stream is the result of the availability of naturally sourced gases from the nearby Buttress- 1 well. The proposed injection formation is a sandy horizon in the Parratte Formation, at a depth of $1435 \mathrm{~m}$ (subsurface). There are two lithofacies in this zone: sand (59\%) and shale (41\%). For the numerical design calculations, the formation is considered heterogeneous and anisotropic, with porosity and permeability correlated to the facies type and conditioned on property values measured down-hole. The average horizontal and vertical sand permeabilities are 1 darcy and 0.01 darcy, respectively; the average porosity is 0.28 . All the shale layers are considered to have 1 milli-darcy permeability.

\subsubsection{Model description}

The injection zone was modeled as a $2 \mathrm{D}$ radial system, extending $1000 \mathrm{~m}$ in the lateral direction and $26 \mathrm{~m}$ in depth. A heterogeneous permeability field is created using an indicator-based algorithm from the geostatistical software library GSLIB in iTOUGH2. The permeability field is generated using a variogram based on data measured at a nearby borehole, and conditioned on the lithologic data and permeability data from the well logs. The correlation length used in the variogram for sand and shale is $400 \mathrm{~m}$ and $300 \mathrm{~m}$, with an anisotropy ratio of 0.0125 and 0.006 , respectively. In the well data analysis, the bin size used for "bed thickness" of each lithofacies is $1 \mathrm{~m}$; therefore, the maximum vertical discretization in the model is $1 \mathrm{~m}$. The residual liquid saturation used in the simulation is 0.16 . The well is perforated between -7 and $-12 \mathrm{~m}$. Vertical discretization of the model is $0.5 \mathrm{~m}$ for the upper $14 \mathrm{~m}$ and $1 \mathrm{~m}$ for the lower $12 \mathrm{~m}$.

In the simulations the injected gas mixture is similar to the $\mathrm{CO}_{2}$ and $\mathrm{CH}_{4}$ ratio in the naturally sourced gas at Otway from the Buttress- 1 well and ignores the higher hydrocarbons which are a small fraction of the gas stream. Supercritical $\mathrm{CO}_{2}$ is injected at a rate of $1.57 \mathrm{~kg} \mathrm{~s}^{-1}$ for 2 days, with $\mathrm{CH}_{4}$ co-injected at a rate of $0.16 \mathrm{~kg} \mathrm{~s}^{-1}$. Water injection rates during hydraulic and tracer testing as well as during the Stage $2 \mathrm{CO}_{2}$ displacement phase is $1.74 \mathrm{~kg} \mathrm{~s}^{-1}$; fluid is produced at a rate of $0.4 \mathrm{~kg} \mathrm{~s}^{-1}$. During thermal testing, the borehole is heated with an intensity of $40 \mathrm{~W} \mathrm{~m}^{-1}$. Krypton $\left({ }^{84} \mathrm{Kr}\right)$ and xenon $\left({ }^{132} \mathrm{Xe}\right)$ are used as inert tracers that partition between the liquid and $\mathrm{CO}_{2}$-rich phases. These parameters were chosen as being operationally feasible using equipment available for the planned test.

\subsubsection{Results}

The proposed test sequence (see Fig. 2 and Table 1) was simulated assuming residual gas saturations of $S_{g r}=0.1, S_{g r}=0.2$, and $S_{g r}=0.35$. Pressure, temperature, and tracer concentrations at the wellbore are recorded and plotted in Figs. 6-8. While the differences between these three cases are pronounced, one has to keep in mind that only a single hydraulic, thermal, and tracer response will be available from the actual tests, i.e., the challenge is to infer the unknown residual gas saturation $S_{g r}$ from a single set of observed pressure, temperature, and tracer concentration curves.

We first look at the system behavior throughout the model domain before we discuss each type of observation data. Fig. 9

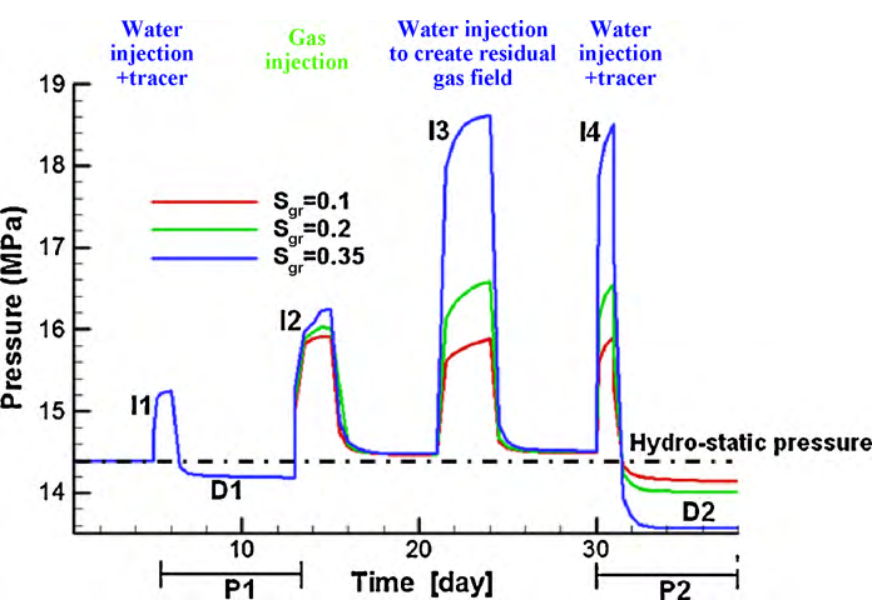

Fig. 6. Pressure responses at the wellbore as a function of time for different residual gas saturations.

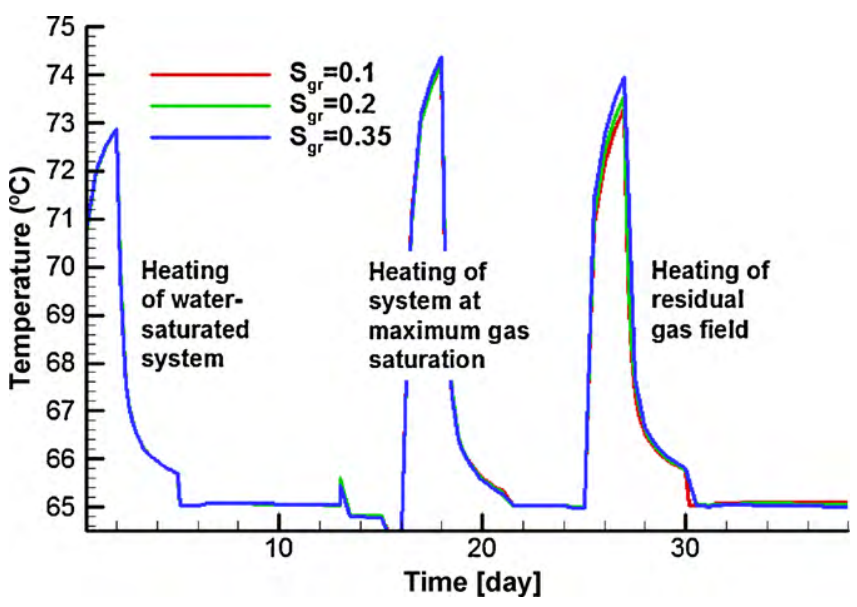

Fig. 7. Temperature responses at the wellbore as a function of time for different residual gas saturations.

shows the gas saturation for a system with $S_{g r}=0.2$ at 15 days (immediately after $\mathrm{CO}_{2}$ injection) and 25 days (immediately after water injection). At day 15 , the system reaches the highest $\mathrm{CO}_{2}$ saturation. Some of the injected gas moves upward from the injection area due to buoyancy effects. At day $25, \mathrm{CO}_{2}$ has moved further away, and the $\mathrm{CO}_{2}$ plume approached the residual saturation of $20 \%$.

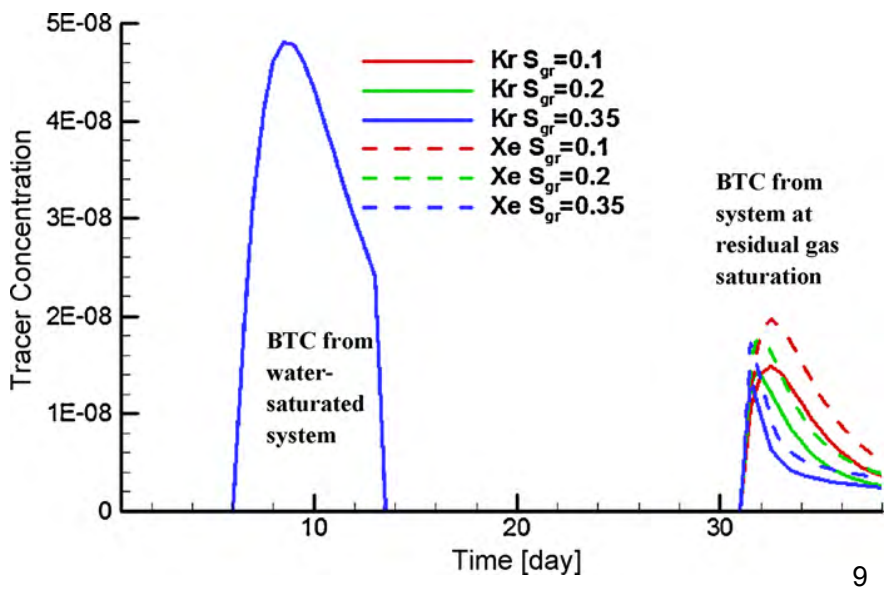

Fig. 8. Tracer breakthrough curves for different residual gas saturations 

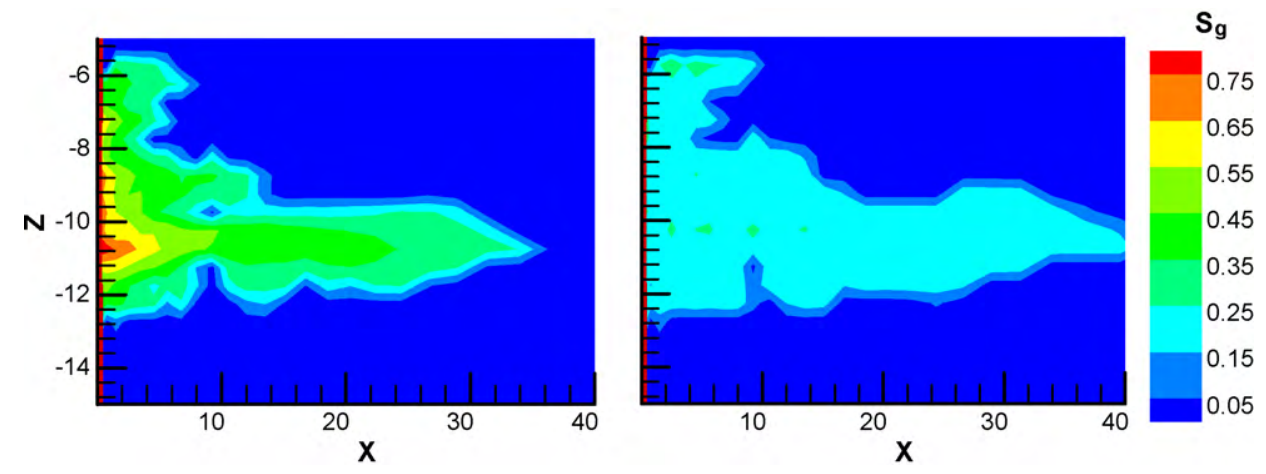

Fig. 9. Gas saturation at (a) 15 days and (b) 25 days for a system with $S_{g r}=0.2$ (injection interval is between -7 and $-12 \mathrm{~m}$ ).

4.2.2.1. Pressure responses. Fig. 6 shows the wellbore pressure as a function of time as calculated for the three residual saturation values. Pressures increase four times during the test sequence in response to (1) water injection into the fully water-saturated system (I1-I4); (2) $\mathrm{CO}_{2}$ injection into the fully water-saturated system (drainage); (3) water injection to displace the $\mathrm{CO}_{2}$ (imbibition), leaving behind a $\mathrm{CO}_{2}$ plume near residual saturation; and (4) water injection into the residual $\mathrm{CO}_{2}$ plume (imbibition). Pressures decrease twice (D1 and D2), i.e., during (1) water production in Stage 1 ; and (2) production of water and $\mathrm{CO}_{2}$ during Stage 3 hydraulic and tracer testing. The pressure responses shown in Fig. 6 can be interpreted as follows:

(1) A comparison of the data from P1 and P2 is useful to infer the residual gas saturation. As discussed above, the curves calculated with different residual gas saturations show the sensitivity of the pressures response to the parameter of interest. Since only one curve will be available for data analysis, information about $S_{g r}$ must be extracted from different time periods of the same curve, as the high sensitivity to residual saturation cannot be directly exploited.

(2) Pressure is only marginally sensitive to residual gas saturation during the $\mathrm{CO}_{2}$ injection phase. The reason for this relative lack of sensitivity is that during gas injection into the water-saturated formation, the total mobility is determined by that of the displaced water phase at full liquid saturation, and the invading gas phase at high gas saturation, both of which being relatively insensitive to $S_{g r}$. If hysteresis were accounted for, the sensitivity would disappear entirely, as the capillary pressure and relative permeabilities follow the primary drainage curves, which do not depend on the residual gas saturation.

(3) The pressure difference between the first and second pressure increases (I1 and I2) is due to the mobility and density contrasts between water and supercritical $\mathrm{CO}_{2}$.

(4) The third and forth pressure increases (I3 and I4) are almost the same because the pressure buildups of these water injection tests are determined by the mobility of the wetting phase near residual gas saturation, which is the same in both cases.

(5) The difference in pressures between the first production (from a fully water-saturated system) and second production (from the formation with trapped $\mathrm{CO}_{2}$ ) can also be used to infer $S_{g r}$, because the pressure decrease in the second test is determined by liquid mobility at $S_{g r}$.

4.2.2.2. Temperature responses. Fig. 7 shows the temperature responses at the wellbore. The three temperature increases correspond to the three heating periods. The last thermal test, conducted with trapped $\mathrm{CO}_{2}$ near the wellbore, shows some sensitivity to the residual gas saturation. The first temperature increase contains information on the wet heat conductivity; the second (when $\mathrm{CO}_{2}$ is at its maximum saturation) contains information on the dry heat conductivity; together, they can be combined with the third temperature increase to infer $S_{g r}$.

4.2.2.3. Tracer breakthrough curves. Tracer breakthrough curves are plotted in Fig. 8. Two noble gases are used as tracers in our simulations: krypton $\left({ }^{84} \mathrm{Kr}\right)$ and xenon $\left({ }^{132} \mathrm{Xe}\right)$. The Henry's coefficients are $3.86 \times 10^{9} \mathrm{~Pa}$ for $\mathrm{Kr}$ and $2.63 \times 10^{9} \mathrm{~Pa}$ for $\mathrm{Xe}$ at $65^{\circ} \mathrm{C}$. By combining the information from two comparisons: (1) comparison of the BTC from the fully water saturated system and the BTC from the residual gas field; and (2) arrival time and tail differences between two different tracer BTCs from the residual gas field, the residual gas saturation can be inferred.

If only one tracer were used in the test, a highly volatile tracer (such as $\mathrm{SF}_{6}$ ) might not be suitable, because a large fraction of a highly volatile tracer would partition into the trapped gas phase, drastically reducing the amount of tracer recoverable in the liquid phase. If multiple partitioning tracers were used, large differences in Henry's coefficient (e.g., the highly volatile tracer $\mathrm{SF}_{6}$ and the highly water soluble refrigerant $\mathrm{r} 134 \mathrm{a}(1,1,1,2$ tetrafluoroethane)) will improve sensitivity to residual $\mathrm{CO}_{2}$ saturation. The use of any particular tracer needs to be supported by laboratory determination of a partitioning coefficient between the gas and water phase at the appropriate reservoir pressure and temperature.

\section{Conclusion}

In this paper, we present a design approach using sensitivity analyses and synthetic inversions to estimate effective residual $\mathrm{CO}_{2}$ saturation from single-well tests. Developing a robust single-well testing methodology is attractive because it obviates the need for drilling multiple wells at the great depths required for geological $\mathrm{CO}_{2}$ storage. Our design approach aims at addressing the challenges for estimating $S_{g r}$ using single-well tests. We propose to (1) conduct a process-based data analysis for accurately representing the multiphase-flow process of the design sequence and determining the information content of observational data and the estimation uncertainty of the parameters of interest; (2) jointly invert $S_{g r}$ using multiple types for reducing the correlations among various parameters; and (3) conduct reference tests under single-phase conditions for reducing the potential bias caused by formation heterogeneity.

To perform the design calculations, we built a physical-based model for a synthetic example and conducted a formal analysis for sensitivity and uncertainty quantification. Both parametric uncertainty and geological uncertainty were considered in the analysis. In addition to $S_{g r}, 11$ parameters including hydrological parameters, thermal parameters, transport parameters, geostatistical parameters, and operational parameters were considered to be uncertain. 10 Results from the modeling analysis indicate that joint data analy- 
sis provides sufficient sensitivity and complementary information to identify $S_{g r}$. Although pressure data from the characterization test are most sensitive to $S_{g r}$, as well as to many other uncertain parameters, we are not able to obtain a unique estimate of $S_{g r}$ using pressure data alone due to correlations among parameters. Combining temperature data and tracer concentration data with pressure data reduces the estimation uncertainty. In addition, the differences between respective tests under single-phase and two-phase conditions reduce ambiguity and correlations among uncertain parameters. Finally, geological uncertainty affects data interpretation, and thus needs to be taken into account when estimating $S_{g r}$ and its uncertainty. Given inherent uncertainty caused by subsurface heterogeneity and measurement errors, the joint inversion of all three data sets and stochastic inversion are proposed as a practical approach to best constrain $S_{g r}$.

Our analyses are performed using both a 2D radial model and a $3 \mathrm{D}$ model. The $2 \mathrm{D}$ radial model has the advantage of being computationally less intensive; however, the radial symmetry leads to an unrealistic heterogeneity pattern. Nevertheless, the two models are in qualitative agreement if they are used to study information content and parametric uncertainty, even though geological uncertainty seems to be more pronounced when a 2D model is used. This indicates the potential appropriateness of using a 2D model at the design stage keeping in mind these limitations.

The synthetic studies provided insights that helped to design a practical field test to be carried out as part of the CO2CRC Otway Project. While the multiple phases of the test are operationally complex, the ability to use a single-well test for accurate appraisal of residual trapping mechanisms can provide considerable overall savings over methods that require multiple boreholes to meet the same objective.

\section{Acknowledgments}

The authors wish to acknowledge the review provided by Christine Doughty from Lawrence Berkeley National Laboratory and thank the two anonymous reviewers for their most useful suggestions. Funding to support this study has been provided by the Assistant Secretary of the Office of Fossil Energy, U.S. Department of Energy, National Energy Technology Laboratory under contract DE-AC02-05CH11231 and through the Australian CO2CRC.

\section{References}

Berger, P.M., Roy, W.R., Mehnert, E., 2009. Geochemical modeling of carbon sequestration, MMV, and EOR in the Illinois Basin, GHGT-9. Energy Procedia 1 (1), 3437-3444, doi:10.1016/j.egypro.2009.02.134.

Cooke, C.E., 1971. Method of Determining Fluid Saturations in Reservoirs, U.S

Davis, B.M., Istok, J.D., Semprini, L., 2002. Push-pull partitioning tracer tests using radon-222 to quantify nonaqueous phase liquid contamination. J. Contam. Hydrol. 58, 129-146.

Davis, B.M., Istok, J.D., Semprini, L., 2005. Numerical simulations of radon as an in situ partitioning tracer for quantifying NAPL contamination using push-pull tests. J. Contam. Hydrol. 78, 87-103.

Dean, H.A., 1971. Method of Determining Fluid Saturations in Reservoirs, U.S.

Deeds, N.E., Pope, G.A., McKinney, D.C., 1999. Vadose zone characterization at a contaminated field site using partitioning interwell tracer technology. Environ. Sci. Technol. 33 (16), 2745-2751.

Doughty, C., 2007. Modeling geologic storage of carbon dioxide: comparison of nonhysteretic and hysteretic characteristic curves. Energy Convers. Manage. 48 (6), 1768-1781.

Finsterle, S., 2004. Multiphase inverse modeling: review and iTOUGH2 applications. Vadose Zone J. 3, 747-762.
Finsterle, S., Kowalsky, M.B., 2008. Joint hydrological-geophysical inversion for soil structure identification. Vadose Zone J. 7, 287-293, doi:10.2136/vzj2006.0078.

Frailey, S.M., Finley, R.J., 2008. Overview of the Illinois Basin's Sequestration Pilots SPE/DOE Symposium on Improved Oil Recovery, Tulsa, Oklahoma, SPE 113418.

Freifeld, B.M., et al., 2009. Recent advances in well-based monitoring of geological carbon sequestration, GHGT-9. Energy Procedia, 2277-2284, doi:10.1016/j.egypro.2009.01.296.

Freifeld, B.M., Finsterle, S., Onstott, T.C., Toole, P.L.M.P., 2008. Ground surface temperature reconstructions: using in situ estimates for thermal conductivity acquired with a fiber-optic distributed thermal perturbation sensor. Geophys. Res. Lett. 35, L14309, doi:10.1029/2008GL034762.

Genuchten, M.T.v, 1980. A closed form equation for predicting the hydraulic conductivity of unsaturated soils. Soil Sci. Soc. Am. J. 44, 892-898.

Giese, R., Henninges, J., Lüth, S., Morozova, D., Schmidt-Hattenberger, C., Würdemann, H., Zimmer, M., Cosma, C.-G., Juhlin, C., CO2SINK Group, 2009. Monitoring at the CO2SINK Site: a concept integrating geophysics, geochemistry and microbiology. Energy Procedia 1 (1), 2251-2259, doi:10.1016/j.egypro.2009.01.293.

Gomez, K., Gonzalez-Gil, G., Schroth, H.M., Zeyer, J., 2008. Transport of methane and noble gases during gas push-pull tests in variably saturated porous media. Environ. Sci. Technol. 42, 2521-2525.

Gonzalez-Gil, G., Schroth, M.H., Zeyer, J., 2007. Transport of methane and noble gases during gas push-pull tests in dry porous media. Environ. Sci. Technol. $41,3262-3268$

Holtz, M., 2006. Optimization of $\mathrm{CO}_{2}$ sequestered as a residual phase in brine-saturated formations, GCCC Digital Publication Series \#06-08, http://www.beg.utexas.edu/gccc/bookshelf/Final\%20Papers/06-08-Final.pdf.

Imhoff, P.T., Jakubowitch, A., Briening, M.L., Chiu, P.C., 2003. Partitioning gas tracer tests for measurement of water in municipal solid waste. J. Air Waste Manage. Assoc. 53 (11), 1391-1400.

IPCC, 2005. Intergovernmental Panel on Climage Change. Special Report on $\mathrm{CO}_{2}$ Capture and Storage, edited, pp. 208-210.

Istok, J.D., Field, J.A., Schroth, M.H., Davis, B.M., Dwarakanath, V., 2002. Single-well push-pull tracer test for NAPL detection in the subsurface. Environ. Sci. Technol. 36, 2708-2716

Jin, M., et al., 1995. Partitioning tracer test for detection, estimation, and remediation performance assessment of subsurface nonaqueous phase liquids. Water Resour. Res. 31, 1201-1211.

Leverett, M.C., 1941. Capillary behavior in porous solids. Trans. AIME 142, 152-169.

Li, L.Q., Imhoff, P.T., 2005. Water saturation measurements by gas tracers in unsaturated porous media-effect of mass transfer limitations. Vadose Zone J. 4 (4), 1107-1118.

Mariner, P.E., Jin, M.Q., Studer, J.E., Pope, G.A., 1999. The first vadose zone partitioning interwell tracer test for nonaqueous phase liquid and water residual. Environ. Sci. Technol. 33 (16), 2825-2828.

Mohammed-Singh, L., Singhal, A.K., Sim, S., 2006. Screening criteria for carbon dioxide huff 'n' puff operations. In: SPE 100044 Proceedings of the SPE/DOE Symposium on Improved Oil Recovery.

Monger, T., Ramos, J., Thomas, J., 1991. Light oil recovery from cyclic $\mathrm{CO}_{2}$ injection: influence of low pressures, impure $\mathrm{CO}_{2}$, and reservoir gas. SPE Reservoir Eng. 6 (1), 25-32.

Nelson, N.T., Oostrom, M., Wietsma, T.W., Brusseau, M.L., 1999. Partitioning tracer method for the in situ measurement of DNAPL saturation: influence of heterogeneity and sampling method. Environ. Sci. Technol. 33 (22), 40464053.

Oldenburg, C.M., Moridis, G., Spycher, N., Pruess, K., 2004. EOS7C Version 1.0: TOUGH2 Module for Carbon Dioxide or Nitrogen in Natural Gas (Methane) Reservoirs. Lawrence Berkeley National Laboratory, Berkeley.

Pruess, K., Oldenburg, C.M., Moridis, G., 1999. TOUGH2 User's Guide, Version 2.0. Lawrence Berkeley National Laboratory, Berkeley.

Pruess, K., Freifeld, B., Kennedy, M., Oldenburg, C.M., Phelps, T.J., van Soest, M.C., 2005. Use of gas phase tracers for monitoring $\mathrm{CO}_{2}$ injection at the Frio test site. In: Fourth Annual Conference on Carbon Capture and Sequestration.

Schroth, M.H., Istok, J.D., Haggerty, R., 2001. In situ evaluation of solute retardation using single-well push-pull tests. Adv. Water Resour. 24, 105-117.

Tang, J.S., Harker, B., 1991. Interwell tracer test to determine residual oil saturation in a gas-saturated reservoir. 1. Theory and design. J. Can. Petrol. Technol. 30 (3), 76-85.

Tomich, J.F., Dalton, R.L., Deans, H.A., Shallenberger, L.K., 1973. Single-well tracer method to measure residual oil saturation. J. Petrol. Technol. 25 (2), 211-218.

Urmann, K., Schroth, M.H., Noll, M., Gonzalez-Gil, G.Z.J., 2008. Assessment of microbial methane oxidation above a petroleum-contaminated aquifer using a combination of in situ techniques. J. Geophys. Res., 113.

Whitley, G.A., McKinney, D.C., Pope, G.A., Rouse, B.A., Deeds, N.E., 1999. Contaminated vadose zone characterization using partitioning gas tracers. J. Environ. Eng.-ASCE 125 (6), 574-582.

Young, C.M., Jackson, R.E., Jin, M., Londergan, J.T., Mariner, P.E., Pope, G.A., Anderson, F.J., Houk, T., 1999. Characterization of a TCE NAPL zone in alluvium by partitioning tracers. Ground Water Monit. Remediat. 19, 84-94. 


\section{DISCLAIMER}

This document was prepared as an account of work sponsored by the United States Government. While this document is believed to contain correct information, neither the United States Government nor any agency thereof, nor The Regents of the University of California, nor any of their employees, makes any warranty, express or implied, or assumes any legal responsibility for the accuracy, completeness, or usefulness of any information, apparatus, product, or process disclosed, or represents that its use would not infringe privately owned rights. Reference herein to any specific commercial product, process, or service by its trade name, trademark, manufacturer, or otherwise, does not necessarily constitute or imply its endorsement, recommendation, or favoring by the United States Government or any agency thereof, or The Regents of the University of California. The views and opinions of authors expressed herein do not necessarily state or reflect those of the United States Government or any agency thereof or The Regents of the University of California.

Ernest Orlando Lawrence Berkeley National Laboratory is an equal opportunity employer. 